\title{
Sensor Nodes Deployment Strategy for Monitoring Roadside Biomass Carbon Stocks of Tourism Destination: A Case of Wulong World Natural Heritage, China
}

\author{
Jun Liu, ${ }^{1,2,3}$ Xi Yang, ${ }^{2}$ Hao Long Liu, ${ }^{3}$ and Zhi Qiao ${ }^{4}$ \\ ${ }^{1}$ Tourism School, Sichuan University, Chengdu 610064, China \\ ${ }^{2}$ College of Tourism and Geography, Chongqing Normal University, No. 12, Tianchen Road, Shapingba District, \\ Chongqing 400047, China \\ ${ }^{3}$ Institute of Geographic Sciences and Natural Resources Research, Chinese Academy of Sciences, A11 Datun Road, \\ Chaoyang District, Beijing 100101, China \\ ${ }^{4}$ State Key Laboratory of Water Environment Simulation, School of Environment, Beijing Normal University, \\ No. 19 Xinjiekouwai Street, Beijing 100875, China
}

Correspondence should be addressed to Zhi Qiao; george@mail.bnu.edu.cn

Received 27 December 2013; Accepted 4 March 2014; Published 7 April 2014

Academic Editor: Fuzhong Nian

Copyright (C) 2014 Jun Liu et al. This is an open access article distributed under the Creative Commons Attribution License, which permits unrestricted use, distribution, and reproduction in any medium, provided the original work is properly cited.

\begin{abstract}
Since the late 1978s, China has experienced one of the highest tourism growth rates in the world, which in turn has driven extensive land-use and land-cover change. The aim of this research is to develop a sensor nodes positioning strategy for detecting land use related dynamics of vegetation carbon stocks of Wulong world natural heritage. Based on the assessment of road networks' influences on biomass carbon stocks, roadside biomass carbon stocks risk index was proposed as a sensor deployment strategy to identify the optimal positions of the sensors to detect the changes in vegetation carbon stocks. Forest and cropland around the lower levels of roads should be the most important region of sensor nodes deployment strategy. The results generated from this study have the ability to achieve optimal solution of spatial positioning problem with minimum number of sensors in biomass carbon monitoring sensor networks. This analysis appears to have great potential for a wide range of practical applications in tourism industry in China.
\end{abstract}

\section{Introduction}

There is now a wide recognition of the urgent need for international governments and industries to reduce and mitigate carbon emissions [1]. Land use change is the second largest contributor of total anthropogenic carbon emissions after the use of fossil fuel [2].

Road networks are recognized as the most pervasive vectors to landscape change [3]. On a global scale, there was nearly $500,000 \mathrm{~km}^{2}$ of land which could be occupied for traffic infrastructure, such as highways, airport, parking sites, and ports [4]. With the explosive growth rates of tourism industry, there follows an inevitable increase in land use. The area used by leisure activities, such as golf course, in the world is about $13,500 \mathrm{~km}^{2}[5,6]$. It is then important to monitor and assess the effects of land cover changes on sequestrations and losses to the carbon stocks of a tourism destination.

Efficiently monitoring land use and cover change is a fundamental part of accurately quantifying the fluxes of carbon to the atmosphere. Sensor networks offer a promise as a tool for remotely gathering real-time data on important carbon dynamics parameters. In all cases, the deployment of sensor nodes affects the effectiveness of vegetation carbon stocks monitoring networks, communication cost, and resource management [7]. However, carbon stock monitoring in developing countries faces numerous problems in deploying sensor network. The main issues include cost and limited understanding of key factors affecting vegetation carbon stocks when placing sensor node. The reason is that there are a variety of factors of environment or society to 
consider, and these factors are not easy to recognize or implement. To improve the efficiency and minimize the total cost while satisfying the desired coverage requirement, a readily indicator that can be used easily to detect the changes in vegetation carbon stocks is required. Once sensors are placed in a position, high quality of monitoring service can be achieved with minimum number of sensor nodes [8].

In this paper, we present roadside biomass carbon stocks risk index as a sensor deployment strategy to identify the optimal positions of the sensors to detect the changes in vegetation carbon stocks. We also present describing how a tourism destination's biomass carbon stocks can be influenced by the expansion of road network. This work has the ability to achieve optimal solution of spatial positioning problem with minimum number of sensors in biomass carbon monitoring sensor networks. This analysis appears to have great potential for a wide range of practical applications in tourism industry in China.

\section{Study Area and Data Resource}

2.1. Study Area. The study was conducted in Wulong County, Chongqing Municipality, China, one of the most famous tourist destinations of China. The study area is located between latitude $29^{\circ} 02^{\prime} \mathrm{N}$ and $29^{\circ} 40^{\prime} \mathrm{N}$ and longitude $117^{\circ} 13^{\prime} \mathrm{E}$ and $108^{\circ} 05^{\prime} \mathrm{E}$ with an area of $2,901 \mathrm{~km}^{2}$ and with a population of 400,000 (Figure 1). The climate in Wulong has distinct four seasons of subtropical monsoon climate type, with average annual temperature of $17.9^{\circ} \mathrm{C}$ and mean annual precipitation of $1,000 \mathrm{~mm}$.

Giant dolines (sinkholes), three Natural Bridges, and Furong Cave of Wulong County represent three of the world's most spectacular examples of humid tropical to subtropical Karst landscapes. It is a part of the South China Karst, a UNESCO World Heritage Site. The unique geological formation and rich cultural heritage of the county prove huge draw for tourists. According to the Wulong Bureau of Statistics, the total tourist arrivals in 2012 were 13 million. The development of tourism industry may result in extensive land-use and land-cover change.

2.2. Data Sources. To retrieve the land-cover types, Landsat TM images were chosen and radiantly corrected. The images were false-color composed of five, four, and three bands using the red-green-blue (RGB) method of artificial visual interpretation. There were six aggregated classes of land use: cropland, forest, grassland, water bodies, built-up land, and bare land. These classes were further divided into 25 landuse classes. The built-up land contains urban land, rural residential land, and industrial and mining sites. The average interpretation accuracies were $92.9 \%$ for land use and $97.6 \%$ for the detection of changes in land cover. For cropland, the accuracy was $94.9 \%$. The built-up area had the highest accuracy of $96.3 \%$. For forest and grassland, the accuracies were $90.1 \%$ and $88.1 \%$, respectively [9]. The land-use datasets were provided by the Institute of Geographical Sciences and Natural Resources Research, Chinese Academy of Sciences.
TABLE 1: The characteristic of different levels of roads in Wulong County.

\begin{tabular}{|c|c|c|}
\hline $\begin{array}{l}\text { The levels } \\
\text { of roads }\end{array}$ & Function & $\begin{array}{l}\text { Average daily } \\
\text { traffic volume }\end{array}$ \\
\hline Road-1 & $\begin{array}{l}\text { The arterial highway connecting the } \\
\text { important political centers and } \\
\text { economic centers }\end{array}$ & $10000 \sim 25000$ \\
\hline Road-2 & $\begin{array}{l}\text { The arterial highway connecting the } \\
\text { political centers and economic } \\
\text { centers }\end{array}$ & $2000 \sim 10000$ \\
\hline Road-3 & The feeder road connecting counties & $200 \sim 2000$ \\
\hline Road-4 & $\begin{array}{l}\text { The feeder road connecting } \\
\text { counties or villages }\end{array}$ & $100 \sim 200$ \\
\hline
\end{tabular}

The study collected two periods of land-use datasets, that is, 1980 and 2005.

In addition, road dataset from the road map of $1: 250000$ (Figure 1) was used to assess roadside biomass carbon stocks risk. The roads were divided into 4 levels based on the task, function, average daily traffic volume of the roads, and actual ecological environment in Wulong County (Table 1).

\section{Methods}

3.1. Fractal Dimension and Stability Index. To calculate the fractal dimension value $(D)$ of land-use type, we make $A$ represent the area of land-use patch and $P$ the perimeter of the same patch. Therefore, the fractal dimension could be defined as $[10,11]$

$$
\sqrt[D]{P}=k \times r^{(1-D) / D} \times \sqrt{A} .
$$

After taking logarithm on both sides of the equation, the above formula could be transformed into the simple formula calculating the fractal dimension value of land-use type. Consider

$$
\operatorname{Ln}(A)=\left(\frac{2}{D}\right) \operatorname{Ln}(P)+C .
$$

The formula indicates the relationship between $D$ and the ratio of the area and perimeter. The theoretical $D$ value ranges from 1 to 2 and reflects the complexity and stability of land-use patch. The greater $D$ value represents more complex mosaic structure for land-use patch. When $D$ value reaches up to 2, the shape of land-use patch is the most complex. Similarly, the $D$ value is smaller, and the spatially mosaic structure is more simple. When $D$ value equals 1 , the landuse patch has a square shape. Suppose that $D$ value is 1.5; the land-use patch is in the random motion of state like Brown movement and represents the most unstable structure.

Therefore, the stability index $(S)$ could be calculated through the following formula. The greater $S$ value represents more stable structure for land use patch. Consider

$$
S=|1.5-D| \text {. }
$$

3.2. The Impact of Roads on Biomass Carbon Stocks. Road constructions can bring severe disturbances to land-use 


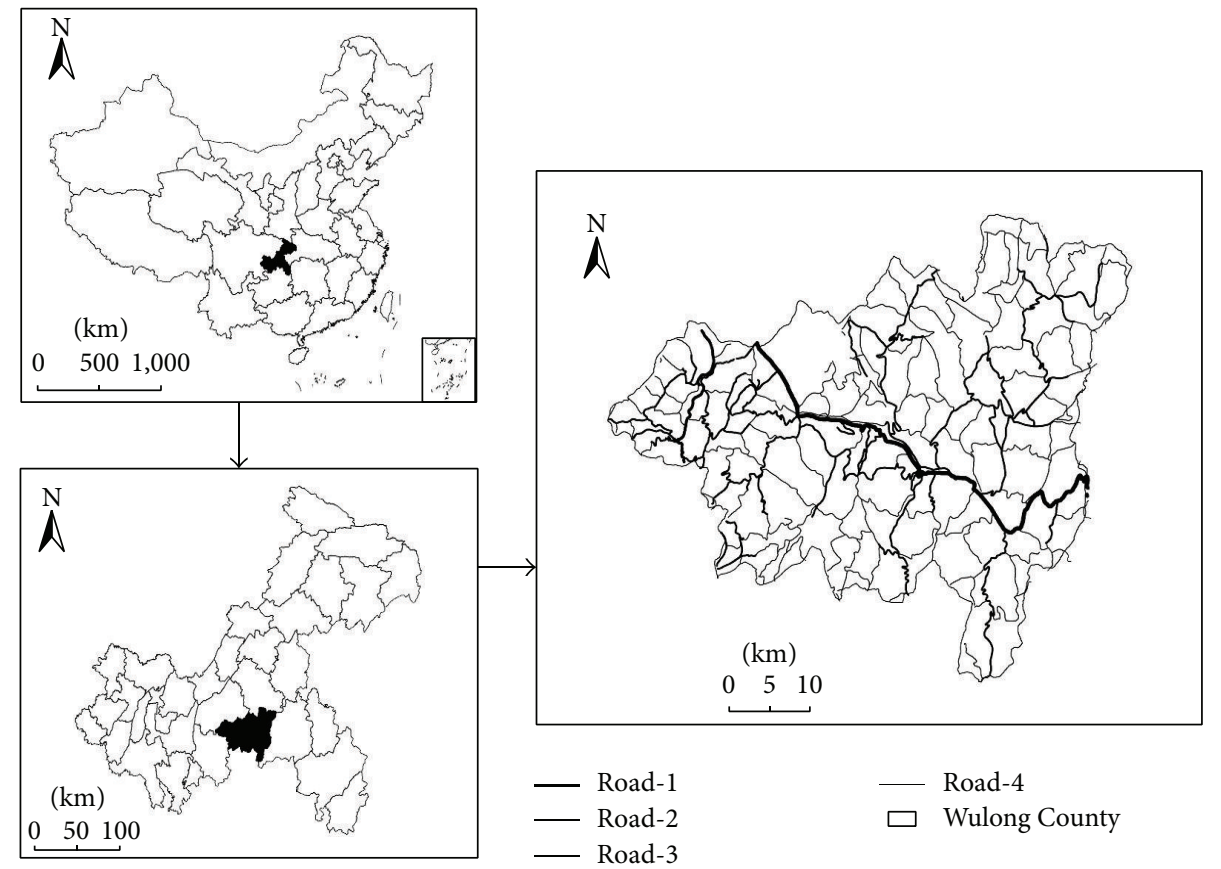

FIGURE 1: The spatial distribution of study area and roads.

TABLE 2: The biomass carbon density.

\begin{tabular}{lcc}
\hline Land use & Carbon density $\left(\mathrm{kg} \cdot \mathrm{m}^{-2}\right)$ & References \\
\hline Cropland & 0.81 & Fang et al., 2007 [14] \\
Forest & 5.41 & Wang et al., $1999[15]$ \\
Grass & 0.42 & Cheng et al., 2012 [16] \\
\hline
\end{tabular}

patches, further affecting biomass carbon stocks [12]. The change of biomass carbon stocks could be calculated as the product of the converted area and the change (gains and losses) of biomass carbon stock per unit area. Consider

$$
L=\sum_{i=1}^{n} A_{i} \times \Delta C d_{i} \times 10^{6}
$$

where $L$ represents the change of biomass carbon stocks $(\mathrm{kg})$, $A$ is the converted area $\left(\mathrm{km}^{2}\right), \Delta C d$ is the change (gains and losses) of biomass carbon density $\left(\mathrm{kg} \cdot \mathrm{m}^{-2}\right)$, and $i$ represents land-use type.

The converted area of land-use types between 1980 and 2005 were calculated by GIS overlay analysis in the paper. Biomass carbon densities of different land-use types were obtained by literature statistics (Table 2).

3.3. The Establishment of Roadside Biomass Carbon Stocks Risk Monitoring Networks. Roads may affect the stability of land-use patches; thereby biomass carbon stocks were also disturbed. Therefore, it is necessary to construct roadside biomass carbon stocks risk monitoring networks from the following two perspectives: the structure of biomass carbon stocks risk and the process of biomass carbon stocks risk, respectively.
Landscape pattern and its change are comprehensive reflections of the regional ecological environment system generated by nature and human behavior. Fractal dimension $\left(D_{i}\right)$ was chosen to reflect the impact of roads construction on landscape pattern in the paper [10]. It can represent the disturbed degree for ecological system in each fishnet. The greater $D_{i}$ value represents less stable structure for ecological system in fishnets. Consider

$$
D_{i}=\sum_{i=1}^{n} \frac{2 \lg \left(P_{i} / 4\right)}{\lg A_{i}},
$$

where $D_{i}$ is the fractal dimension in each fishnet, $P_{i}$ is the perimeter of landscape patch in each fishnet, and $A_{i}$ is the area of landscape patch in each fishnet.

To quantitatively calculate the relationship between the construction of roads and the biomass carbon stocks, carbon density index was applied in the paper. The carbon density index $\left(P_{i}\right)$ was calculated based on carbon density $\left(C d_{i}\right)$ of the different land-use types and their proportions in each fishnet. Consider

$$
P_{i}=\sum_{i=1}^{n} C d_{i} \times \frac{A_{i}}{A},
$$

where $P_{i}$ is the carbon density index of each fishnet, $C d_{i}$ is the carbon density of different land use types, $A_{i}$ is the area of all land-use types, $A$ is the area of fishnet, and $A_{i} / A$ is the proportion of each land-use type in individual fishnet. The higher $P_{i}$ represents the higher biomass carbon stocks loss resulting from the ecosystem's damage in the fishnet.

Landscape pattern can represent the process of ecosystem change. To ecological risk, the process of ecosystem change 


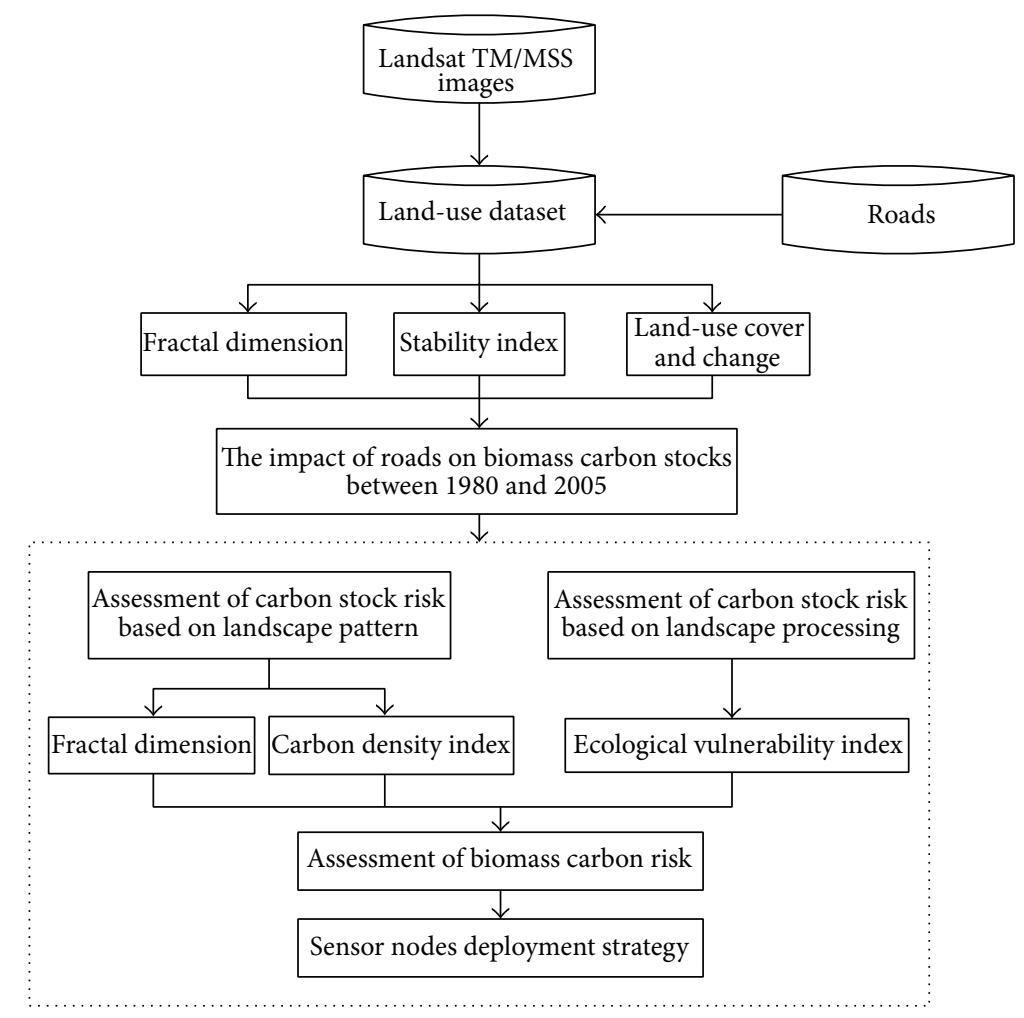

FIGURE 2: The flow chart of sensor nodes deployment strategy for monitoring roadside biomass carbon stocks.

shows the responses of different landscape types to outside disturbances. Different landscape types play different poles in maintaining and improving overall ecological structure and function and promoting natural evolution of ecological system. Meanwhile, they have different abilities to resist outside disturbances. Their subsequent ecological effects are obviously different because of different degrees and patterns of damage in different landscape regions. Ecological vulnerability index was used to reflect the impact of the construction of road on the process of biomass carbon stocks risk.

Based on the impact assessment of roads to different landuse types, the vulnerability values were given as urban land, cropland, grass, forest, water body, and rural residential area to $6,5,4,3,2$, and 1 . We finally calculated the ecological vulnerability index $\left(\mathrm{EVI}_{i}\right)$ of each fishnet [13]. Consider

$$
\mathrm{EVI}_{i}=\sum_{i=1}^{n} V_{i} \times \frac{A_{i}}{A}
$$

where $\mathrm{EVI}_{i}$ is the ecological vulnerability index of each fishnet, $V_{i}$ is the vulnerability value of different land-use types, $A_{i}$ is the area of all land-use types, $A$ is the area of fishnet, and $A_{i} / A$ is the proportion of each land-use type in individual fishnet. The higher $\mathrm{EVI}_{i}$ represents the higher biomass carbon stocks risk in the fishnet.

Finally, we calculated the roadside biomass carbon stocks risk index $\left(R_{i}\right)$

$$
R_{i}=\alpha D_{i}+\beta P_{i}+\delta \mathrm{EVI}_{i},
$$

where $R_{i}$ represents the risk degree of biomass carbon stocks affected by roads construction. $\alpha, \beta, \delta$ are given as $0.2,0.5,0.3$. It is worth noting that $D_{i}, P_{i}$, and $\mathrm{EVI}_{i}$ should be normalized before calculating the $R_{i}$ in each fishnet.

The size of fishnet was $1000 \mathrm{~m} \times 1000 \mathrm{~m}$. The study area was masked by the $1 \mathrm{~km}$ buffers of roads. Thus, the value of roadside biomass carbon stocks risk could be calculated. The calculated raster was reclassified into the roadside biomass carbon stocks risk grades by density separation. The results suggest that the classification map would be effective for monitoring roadside biomass carbon stocks risk and sensor nodes deployment strategy (Figure 2).

\section{Results}

4.1. The Impact of Roads on Land Use Stability. The impact of roads on land use stability was quantitatively calculated through overlay analysis and buffer analysis based on ArcGIS platform. Within the $1 \mathrm{~km}$ buffers of the four levels of roads, the stability indices were $0.04,0.12,0.17$, and 0.17 , respectively. Obviously the higher level of roads had the more serious impact on land use stability.

There were distinct differences for the impacts of different levels of roads on the various land-use types (Tables 3, 4, 5, 6). The stability of cropland was the worst in the $1 \mathrm{~km}$ buffer of Road-1. The stability index of cropland was 0.03 under the above circumstances, followed by forest; the stability index of forest was 0.06 . The rural residential area and urban land had higher stability indices, 0.68 and 0.27 , respectively. 
TABLE 3: The impact of Road-1 on land use stability.

\begin{tabular}{lcccc}
\hline Land use & $\begin{array}{c}\text { The regression formula } \\
\text { between area and perimeter }\end{array}$ & $R^{2}$ & $D$ & $S$ \\
\hline Cropland & $y=1.365 x+0.715$ & 0.94 & 1.47 & 0.03 \\
$\begin{array}{l}\text { Forest } \\
\text { Grass }\end{array}$ & $y=1.393 x+0.664$ & 0.94 & 1.44 & 0.06 \\
Water body & $y=1.173 x+1.739$ & 0.92 & 1.71 & 0.21 \\
$\begin{array}{l}\text { Urban land } \\
\begin{array}{l}\text { Rural residential } \\
\text { area }\end{array}\end{array}$ & $y=1.623 x-0.603$ & 0.94 & 1.23 & 0.27 \\
$\begin{array}{l}\text { All land-use } \\
\text { patches }\end{array}$ & $y=2.439 x-4.699$ & 0.99 & 0.82 & 0.68 \\
\hline
\end{tabular}

TABLE 4: The impact of Road-2 on land-use stability.

\begin{tabular}{|c|c|c|c|c|}
\hline Land use & $\begin{array}{l}\text { The regression formula } \\
\text { between area and perimeter }\end{array}$ & $R^{2}$ & $D$ & $S$ \\
\hline Cropland & $y=1.432 x+0.581$ & 0.93 & 1.40 & 0.10 \\
\hline Forest & $y=1.395 x+0.855$ & 0.96 & 1.43 & 0.07 \\
\hline Grass & $y=1.692 x-0.720$ & 0.92 & 1.18 & 0.32 \\
\hline \multicolumn{5}{|l|}{ Water body } \\
\hline \multicolumn{5}{|l|}{ Urban land } \\
\hline \multicolumn{5}{|l|}{$\begin{array}{l}\text { Rural residential } \\
\text { area }\end{array}$} \\
\hline $\begin{array}{l}\text { All land-use } \\
\text { patches }\end{array}$ & $y=1.453 x+0.503$ & 0.94 & 1.38 & 0.12 \\
\hline
\end{tabular}

The effect on grass was the largest in the $1 \mathrm{~km}$ buffer of Road2 . The stability index of forest was 0.07 , followed by cropland; the stability index of cropland was 0.10 . There was no rural residential area and urban land in the $1 \mathrm{~km}$ buffer of Road-2. Road-3 strongly impacted urban land, followed by grass and cropland; the stability indices were 0.12 and 0.16 , respectively. Rural residential area showed good stability, and the effect on water body was slight in the $1 \mathrm{~km}$ buffer of Road-3. The effect of Road- 4 on urban land was the the largest and its stability index was 0.09 , followed by cropland. Similarly, rural residential area showed the highest stability; its stability index was 0.52. Comparing the impacts of different levels of roads on six kinds of land uses, the lower level of roads strongly impacted urban land. By contrast, the impacts on natural ecosystems (cropland, forest, and grass) were higher in the buffer of higher levels of roads. However, rural residential area and water body overall showed superior stability.

\subsection{Estimating Roadside Biomass Carbon Stocks Changes.} The total area of land-use change was $121.67 \mathrm{~km}^{2}$ between 1980 and 2005 (Table 7). Grass, cropland, and forest had the larger converted area. The areas transferring from grass and cropland were $69.19 \mathrm{~km}^{2}$ and $30.70 \mathrm{~km}^{2}$, accounting for $14.50 \%$ and $3.59 \%$ of their individual area in 1980 . The area of forest increased by $86.25 \mathrm{~km}^{2}$, accounting for $5.68 \%$ of the total area in 1980. The area of water body and rural residential area increased by $8.75 \mathrm{~km}^{2}$ and $0.18 \mathrm{~km}^{2}$,
TABLE 5: The impact of Road-3 on land-use stability.

\begin{tabular}{lcccc}
\hline Land use & $\begin{array}{c}\text { The regression formula } \\
\text { between area and perimeter }\end{array}$ & $R^{2}$ & $D$ & $S$ \\
\hline Cropland & $y=1.495 x+0.152$ & 0.92 & 1.34 & 0.16 \\
Forest & $y=1.566 x-0.268$ & 0.94 & 1.28 & 0.22 \\
Grass & $y=1.445 x+0.408$ & 0.94 & 1.38 & 0.12 \\
Water body & $y=1.731 x-1.085$ & 0.97 & 1.16 & 0.34 \\
Urban land & $y=1.329 x+0.942$ & 0.79 & 1.50 & 0.00 \\
$\begin{array}{l}\text { Rural residential } \\
\text { area }\end{array}$ & $y=2.252 x-3.781$ & 0.99 & 0.89 & 0.61 \\
$\begin{array}{l}\text { All land-use } \\
\text { patches }\end{array}$ & $y=1.503 x+0.101$ & 0.93 & 1.33 & 0.17 \\
\hline
\end{tabular}

TABLE 6: The impact of Road-4 on land-use stability.

\begin{tabular}{lcccc}
\hline Land use & $\begin{array}{c}\text { The regression formula } \\
\text { between area and perimeter }\end{array}$ & $R^{2}$ & $D$ & $S$ \\
\hline Cropland & $y=1.464 x+0.292$ & 0.92 & 1.37 & 0.13 \\
Forest & $y=1.547 x-0.179$ & 0.94 & 1.29 & 0.21 \\
Grass & $y=1.603 x-0.499$ & 0.94 & 1.25 & 0.25 \\
Water body & $y=1.785 x-1.267$ & 0.98 & 1.12 & 0.38 \\
Urban land & $y=1.256 x+1.359$ & 0.65 & 1.59 & 0.09 \\
$\begin{array}{l}\text { Rural residential } \\
\text { area }\end{array}$ & $y=2.036 x-2.686$ & 0.95 & 0.98 & 0.52 \\
$\begin{array}{l}\text { All land-use } \\
\text { patches }\end{array}$ & $y=1.500 x+0.095$ & 0.93 & 1.33 & 0.17 \\
\hline
\end{tabular}

respectively. Although the area of urban land increased by $4.71 \mathrm{~km}^{2}$, the proportion increased by $348.89 \%$.

The total biomass carbon stocks were $9.11 \times 10^{9} \mathrm{~kg}$ in Wulong County in 1980, and it reached up to $9.52 \times 10^{9} \mathrm{~kg}$ in 2005. The increased carbon stocks accounted for $4.53 \%$ of the total stocks in 1980. The carbon stocks of forest increased by $4.66 \times 10^{8} \mathrm{~kg}$. Cropland and grass decreased by $2.4 \times 10^{7} \mathrm{~kg}$ and $2.9 \times 10^{7} \mathrm{~kg}$, respectively.

The roads had strong influences on land-use change. The converted area was $86.6 \mathrm{~km}^{2}$ in the $1 \mathrm{~km}$ buffer of roads, accounting for $71.18 \%$ of the total converted area during the period of 1980 2005. Consequently, biomass carbon stocks increased by $2.84 \times 10^{8} \mathrm{~kg}$ resulting from land-use change, accounting for $68.77 \%$ of the total increment.

There were different changes of biomass carbon stocks in the $1 \mathrm{~km}$ buffers of different levels of roads. Biomass carbon stocks increased by $14.80 \times 10^{6} \mathrm{~kg}, 0.29 \times 10^{6} \mathrm{~kg}, 131.73 \times$ $10^{6} \mathrm{~kg}$, and $213.08 \times 10^{6} \mathrm{~kg}$ in the $1 \mathrm{~km}$ buffers of the four levels of roads, respectively. The increment in the buffer of Road4 accounted for $51.63 \%$ of the total biomass carbon stocks change between 1980 and 2005. Apparently, biomass carbon stocks increased more distinctly under the influences of the lower level of roads.

Forest was the most obvious land-use type for biomass carbon stocks change. The losses of biomass carbon stocks resulting from the area converting from forest to other landuse types were $2.46 \times 10^{6} \mathrm{~kg}, 0,1.13 \times 10^{7} \mathrm{~kg}$, and $3.42 \times 10^{7} \mathrm{~kg}$, respectively. Conversely, the increments of biomass carbon 


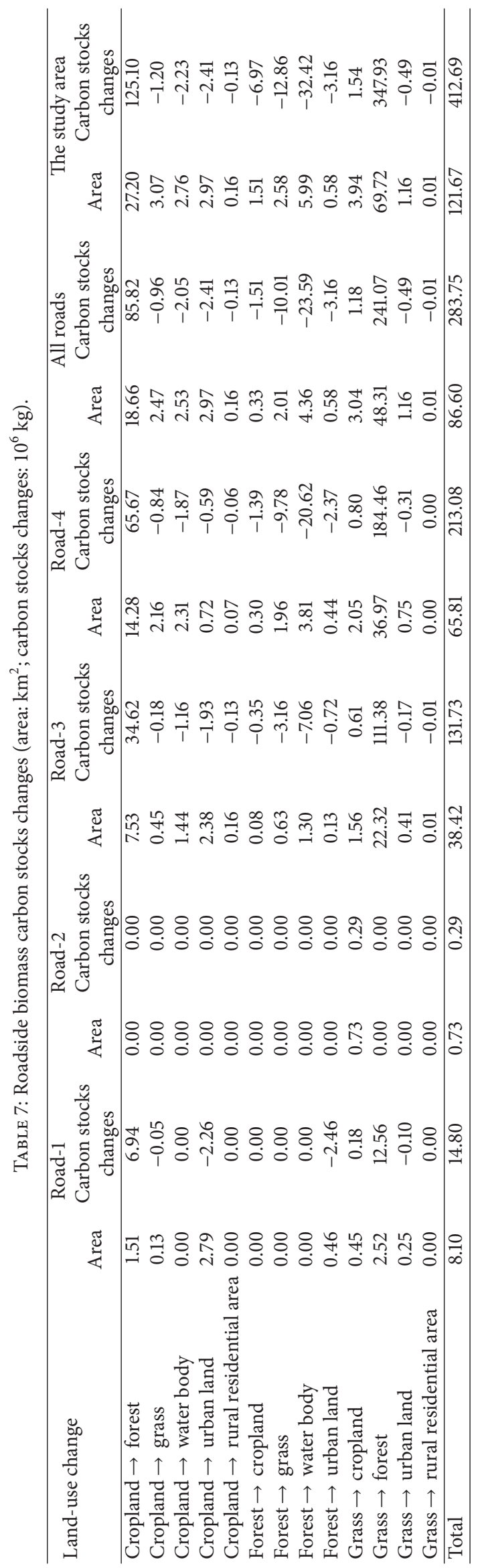




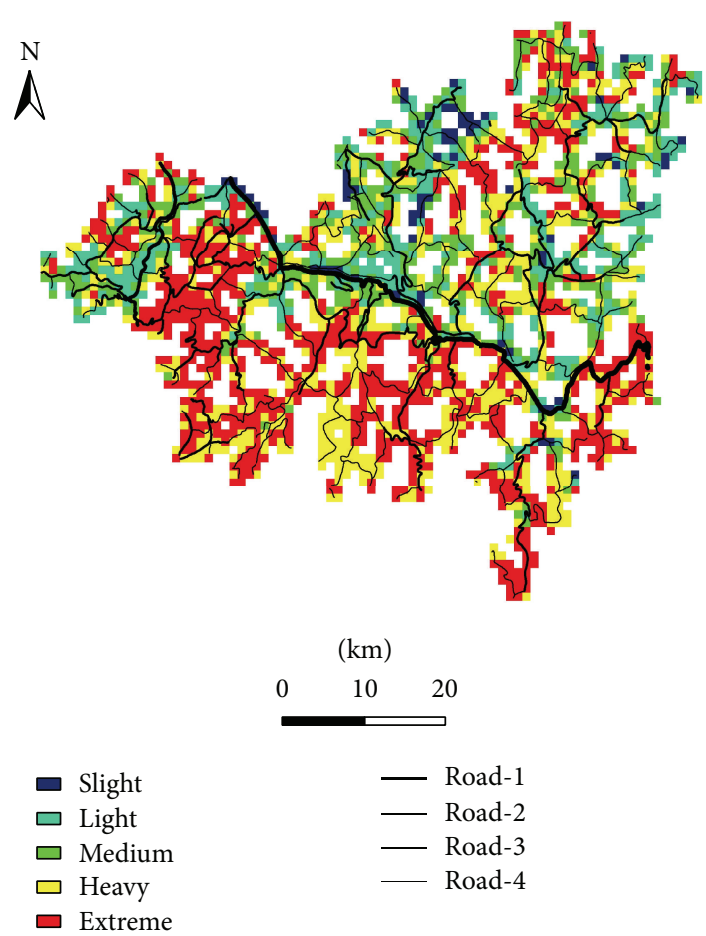

FIGURE 3: The spatial pattern of roadside biomass carbon stocks risk regions.

stocks resulting from the area converting from other land-use types to forest were $1.95 \times 10^{7} \mathrm{~kg}, 0,1.46 \times 10^{8} \mathrm{~kg}$, and $2.50 \times$ $10^{8} \mathrm{~kg}$, respectively. In conclusion, biomass carbon stocks of forest changed more distinctly under the influences of the lower level of roads. In addition, the losses of biomass carbon stocks resulting from the area converting from other land-use types to urban land were $4.83 \times 10^{6} \mathrm{~kg}, 0,2.82 \times 10^{6} \mathrm{~kg}$, and $3.27 \times 10^{6} \mathrm{~kg}$, respectively. There was stronger influence on biomass carbon stocks resulting from urban land change in the buffer of higher level of road.

4.3. Establishing Roadside Biomass Carbon Stocks Risk Monitoring Networks. Roadside biomass carbon stocks risk was divided into five levels, slight, light, medium, heavy, and extreme (Figure 3). The area of risk regions extended with the increase of risk level. Comparing the spatial distribution of the five risk regions, the study area was divided into two parts by the Road-1; the risk degree was smaller in north than in south. Extreme risk region and heavy risk region mainly are distributed in south, and medium risk region and light risk region are widely distributed in north of Wulong County. The area of extreme risk region was $795 \mathrm{~km}^{2}$, accounting for $35.83 \%$ of all risk regions, followed by heavy risk region with the area of $623 \mathrm{~km}^{2}$. The areas of light risk region and medium risk region were $340 \mathrm{~km}^{2}$ and $390 \mathrm{~km}^{2}$, accounting for $15.32 \%$ and $17.58 \%$ of all risk regions, respectively. The area of slight risk region was $71 \mathrm{~km}^{2}$, accounting for $3.20 \%$ of all risk regions.

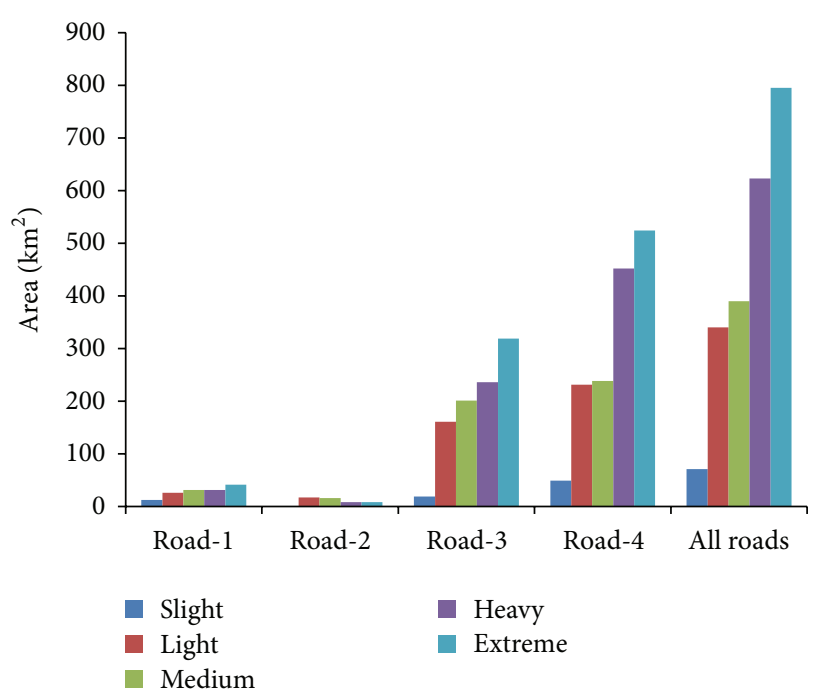

FIGURE 4: Roadside biomass carbon stocks risk for different levels of roads.

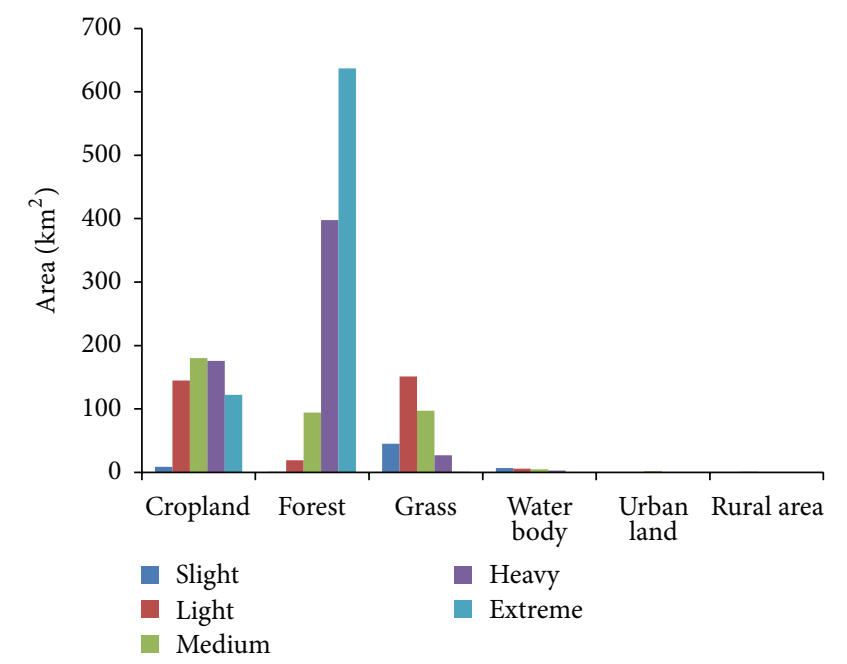

Figure 5: Roadside biomass carbon stocks risk for different land use types.

The areas of different risk regions in the influence domain of the four levels of roads were calculated (Figure 4). The area of extreme risk region in the influence domain of Road4 reached up to $524 \mathrm{~km}^{2}$, accounting for $65.92 \%$ of the area of extreme risk region. The area of heavy risk region in the influence domain of Road-4 reached up to $452 \mathrm{~km}^{2}$, accounting for $72.55 \%$ of the area of heavy risk region. The area of extreme risk region in the influence domain of Road1 and Road- 2 accounted for $5.16 \%$ and $1.01 \%$ of the area of extreme risk region. Therefore, the lower level of roads was the high risk areas threatening biomass carbon stocks. It has to highly regard protecting biomass carbon stocks around the lower level of roads.

The areas of different land-use types in all risk regions were calculated (Figure 5). The area of forest in the extreme risk region reached up to $637 \mathrm{~km}^{2}$, accounting for $83.82 \%$ of 
the area of extreme risk region. The area of cropland in the extreme risk region was $122 \mathrm{~km}^{2}$, accounting for $16.05 \%$ of the area of extreme risk region. In the heavy risk region, the area of forest was $398 \mathrm{~km}^{2}$, accounting for $65.89 \%$ of the area of heavy risk region. The proportion of cropland reached up to $29.14 \%$, meanwhile the proportion of grass reached up to $4.47 \%$. In the medium risk region, the area of cropland was higher than forest, and the area of cropland was $180 \mathrm{~km}^{2}$, accounting for $47.62 \%$. The forest and grass accounted for $24.87 \%$ and $25.66 \%$, respectively. Biomass carbon stocks should be protected in forest and cropland.

\section{Discussion}

This paper developed a sensor nodes positioning strategy for detecting land use related dynamics of biomass carbon stocks of a tourism destination. Roadside biomass carbon stocks risk index was proposed based on the assessment of impact of road networks on land-use stability and biomass carbon stocks changes. Roadside biomass carbon stocks risk monitoring networks could be established through the assessment of biomass carbon stocks risk taking into account the structure of biomass carbon stocks risk and the process of biomass carbon stocks risk.

The higher level of roads had the more serious impact on land use stability. There was more vigorous influence on biomass carbon stocks resulting from urban land change in the buffer of higher level of road. Meanwhile, biomass carbon stocks changed more distinctly under the influences of the lower level of roads. The lower level of roads was the high risk areas threatening biomass carbon stocks. Forest and cropland mainly were the most important components of the high risk areas. In conclusion, forest and cropland around the lower levels of roads should be the important region of sensor nodes deployment strategy. Roadside biomass carbon stocks risk monitoring networks may thus be an effective approach to protect the biomass carbon stocks in tourism industry in China.

\section{Conflict of Interests}

The authors declare that there is no conflict of interests regarding the publication of this paper.

\section{Acknowledgments}

This study was supported by the National Natural Science Foundation of China (NSFC, no. 41101115), China Postdoctoral Science Foundation (no. 2011M500376), and Chongqing City Board of Education Science and Technology Project (no. KJ100603).

\section{References}

[1] I. J. Smith and C. J. Rodger, "Carbon emission offsets for aviation-generated emissions due to international travel to and from New Zealand," Energy Policy, vol. 37, no. 9, pp. 3438-3447, 2009.
[2] R. J. Scholes and I. R. Noble, "Storing carbon on land," Science, vol. 294, no. 5544, pp. 1012-1013, 2001.

[3] R. T. T. Forman, D. Sperling, and J. A. Bissonette, Road Ecology: Science and Solutions, Island Press, Washington, DC, USA, 2003.

[4] S. Gössling, "Global environmental consequences of tourism," Global Environmental Change, vol. 12, no. 4, pp. 283-302, 2002.

[5] A. M. Rico-Amoros, J. Olcina-Cantos, and D. Sauri, “Tourist land use patterns and water demand: evidence from the Western Mediterranean," Land Use Policy, vol. 26, no. 2, pp. 493-501, 2009.

[6] A. M. Williams and G. Shaw, "Future play: tourism, recreation and land use," Land Use Policy, vol. 26, supplement 1, pp. S326S335, 2009.

[7] Y. Zou and K. Chakrabarty, "Sensor deployment and target localization in distributed sensor networks," Transactions on Embedded Computing Systems, vol. 3, no. 1, pp. 61-91, 2004.

[8] K. Nikitha, B. R. Thella, and R. L. Davuluri, "Sensor deployment using particle swarm optimization," International Journal of Engineering Science and Technology, vol. 2, no. 10, pp. 5395-5401, 2010.

[9] J. Liu, M. Liu, H. Tian et al., "Spatial and temporal patterns of China's cropland during 1990-2000: an analysis based on Landsat TM data," Remote Sensing of Environment, vol. 98, no. 4, pp. 442-456, 2005.

[10] M. Batty and P. A. Longley, "Fractal-based description of urban form," Environment \& Planning B, vol. 14, no. 2, pp. 123-134, 1987.

[11] R. White and G. Engelen, "Cellular automata and fractal urban form: a cellular modelling approach to the evolution of urban land-use patterns," Environment \& Planning A, vol. 25, no. 8, pp. 1175-1199, 1993.

[12] S. L. Liu, B. S. Cui, S. K. Dong, Z. F. Yang, M. Yang, and K. Holt, "Evaluating the influence of road networks on landscape and regional ecological risk-A case study in Lancang River Valley of Southwest China," Ecological Engineering, vol. 34, no. 2, pp. 91-99, 2008.

[13] Z. Qiao, X. Yang, J. Liu, and X. L. Xu, "Ecological vulnerability assessment integrating the spatial analysis technology with algorithms: a case of the wood-grass ecotone of northeast China," Abstract and Applied Analysis, vol. 2013, Article ID 207987, 8 pages, 2013.

[14] J. Y. Fang, Z. D. Guo, S. L. Piao, and A. P. Chen, "Terrestrial vegetation carbon sinks in China, 1981-2000," Science in China D: Earth Sciences, vol. 50, no. 9, pp. 1341-1350, 2007 (Chinese).

[15] S. Q. Wang, C. H. Zhou, and C. W. Luo, "Studying carbon storage spatial distribution of terrestrial natural vegetation in China," Progress in Geography, vol. 18, no. 3, pp. 238-244, 1999 (Chinese).

[16] J. M. Cheng, J. Cheng, X. M. Yang, W. Liu, and F. R. Chen, "Spatial distribution of carbon density in grassland vegetation of the Loess Plateau of China," Acta Ecologica Sinica, vol. 32, no. 1, pp. 226-237, 2012. 


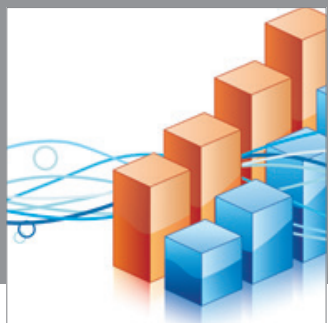

Advances in

Operations Research

mansans

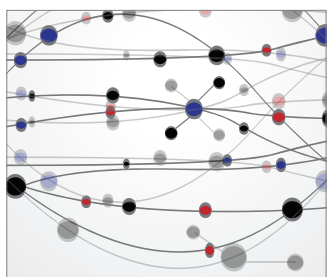

The Scientific World Journal
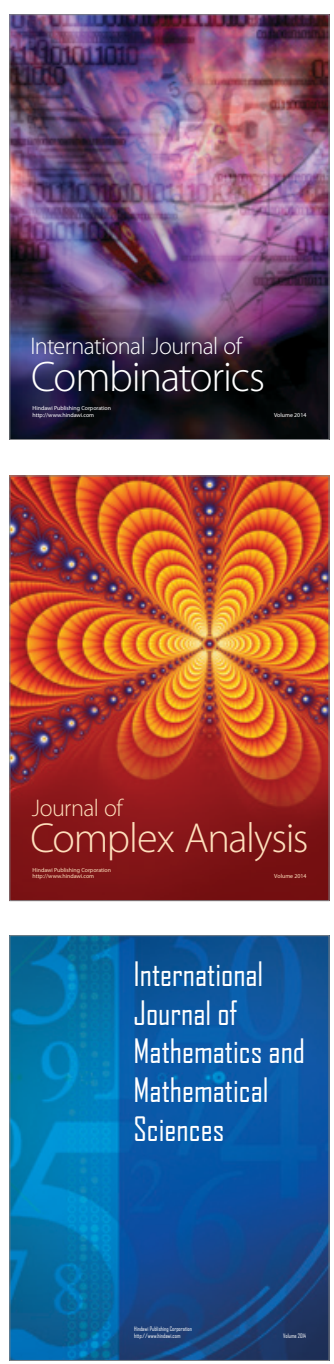
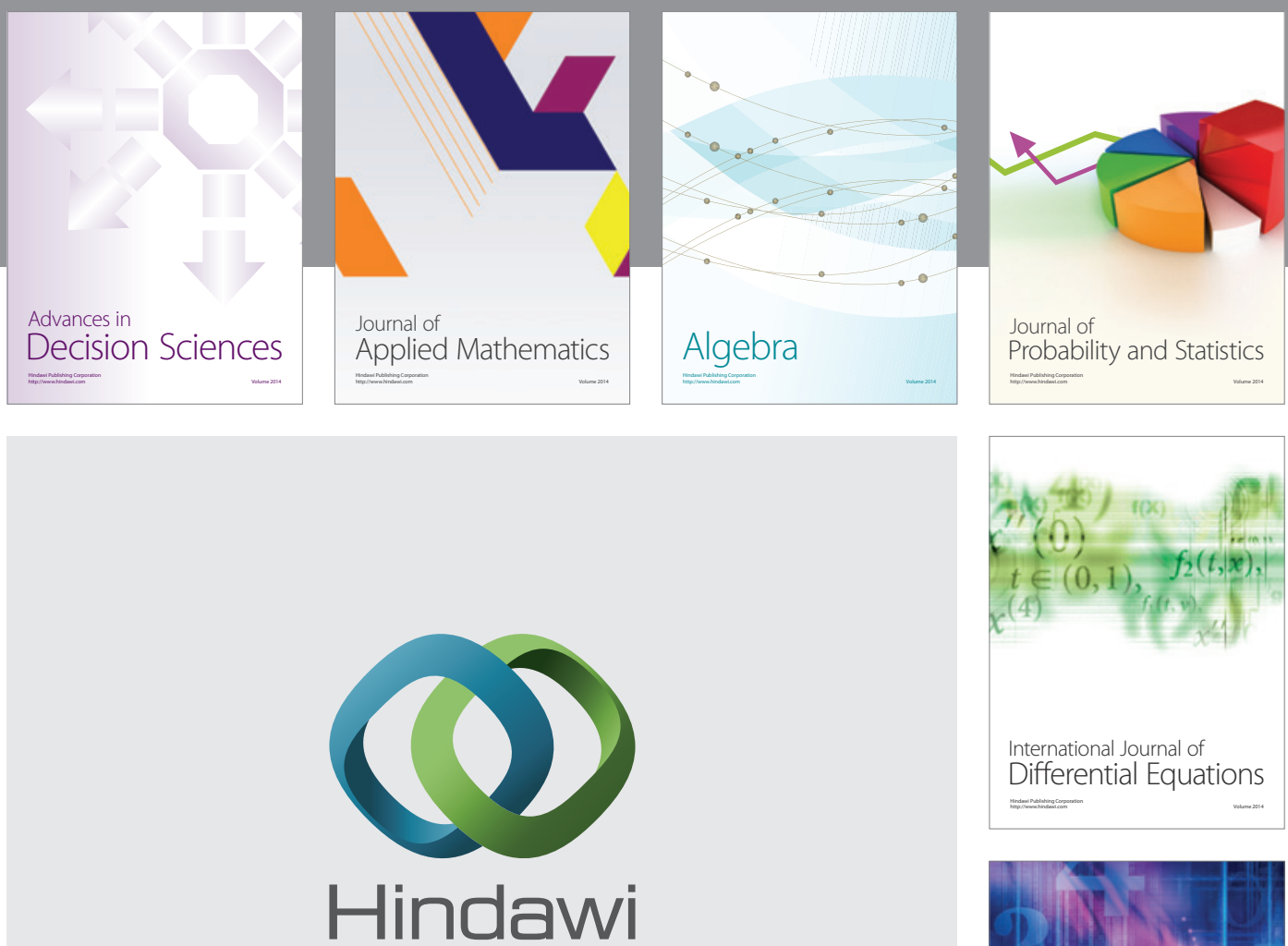

Submit your manuscripts at http://www.hindawi.com
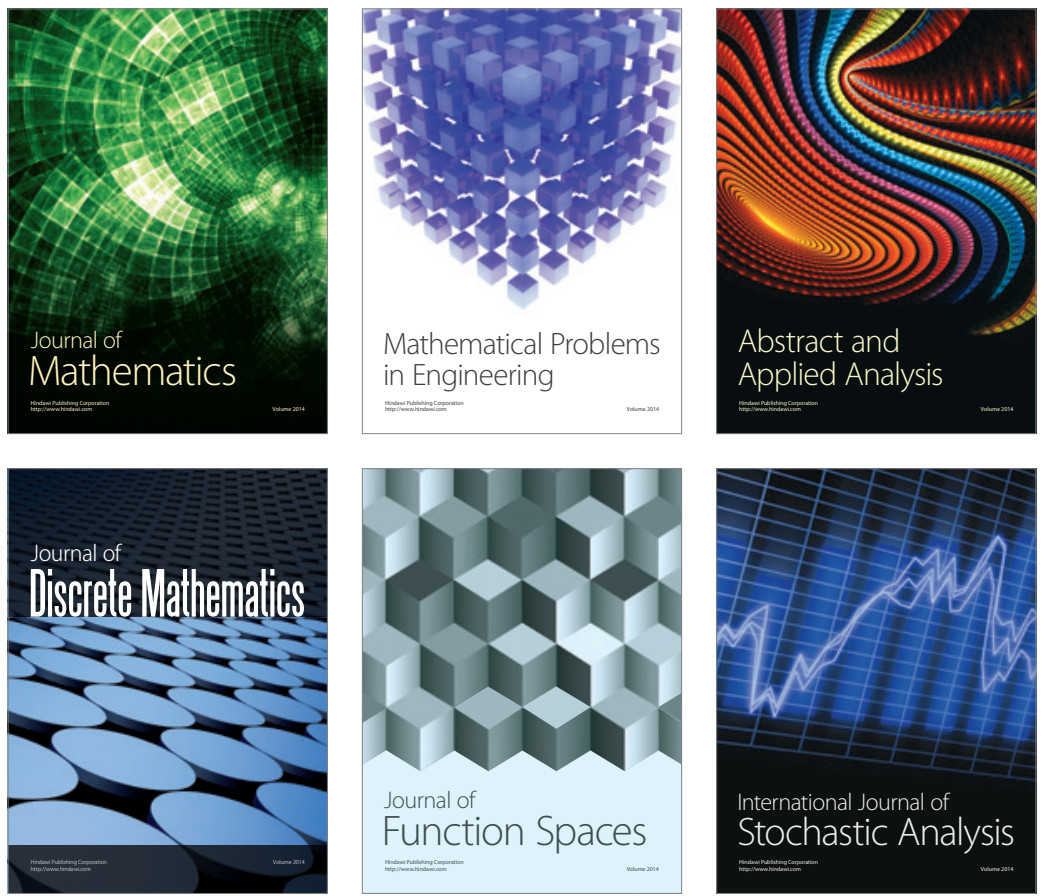

Journal of

Function Spaces

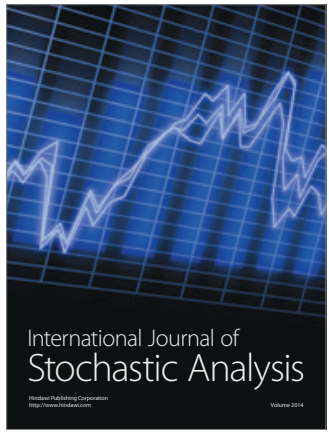

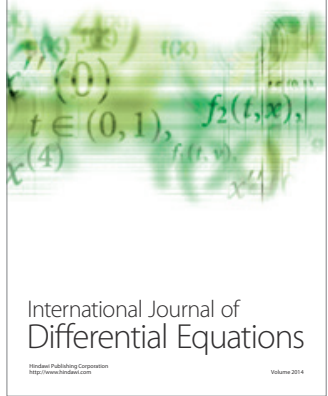
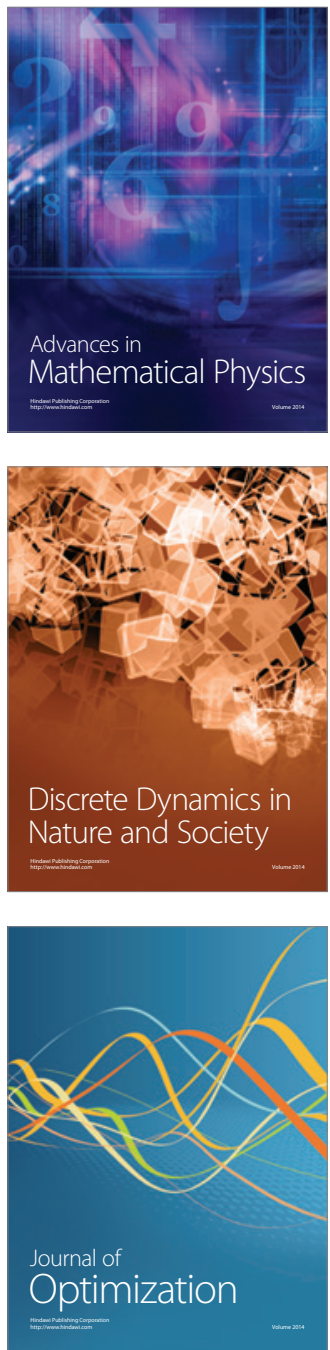